\title{
Nature's Notebook-A Tool for Recording the Timing of Seasonal Activity of Plants and Animals
}

\section{What is Nature's Notebook?}

Nature's Notebook is a customizable program used by individual observers and Federal Government partners to document patterns in phenology - the timing of seasonal activity of plants and animals over the course of the calendar year. The USA National Phenology Network (USANPN) established Nature's Notebook in 2009 to create a standard approach for collecting phenology data on plants and animals across

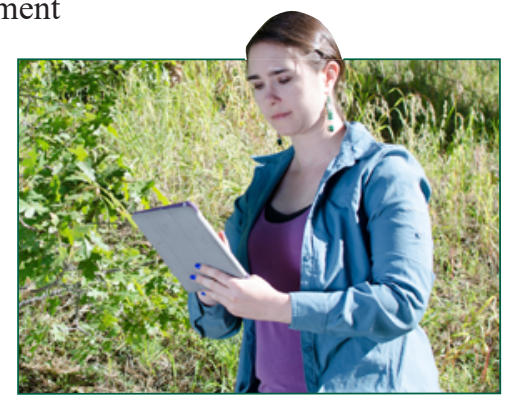

An observer collecting data with the Nature's Notebook mobile application. the country. Currently, about half of the data are submitted by independent backyard observers at individual sites and half are submitted by groups of participants as part of a Local Phenology Program (LPP). Figure 1 shows locations for which independent observers and LPP participants have submitted data.

\section{USA National Phenology Network}

With support from the U.S. Geological Survey (USGS), the USA-NPN collects, organizes, and shares data on phenology-

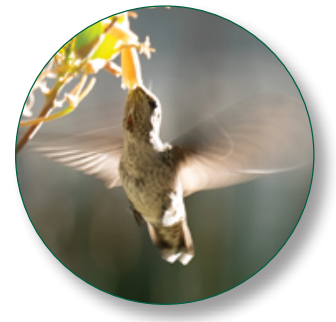
the timing of seasonal activity of plants and animals. This information aids decision making, scientific discovery, and the development of a broader understanding of phenology.

\section{Nature's Notebook. What We Offer}

Scientifically vetted observation protocols for more than 1,300 species

Training materials including observation guidelines, guides to understanding botany, Nature's Notebook protocols, quizzes to test your knowledge, and video tutorials

Mobile application (app) and paper datasheet options for data entry

Data access and visualization tools

Participation incentives such as accomplishment badges and leaderboards

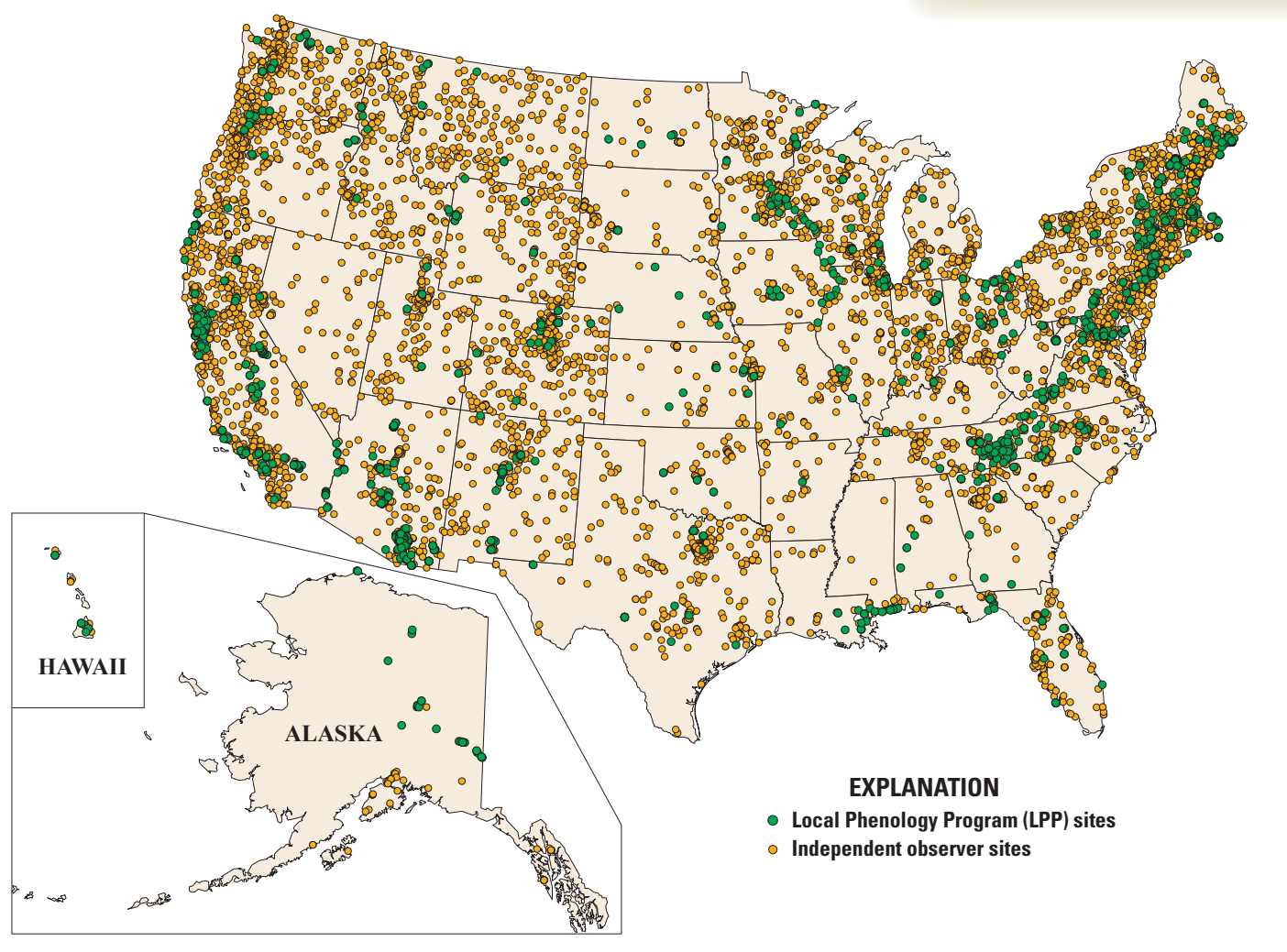

Figure 1. Map showing locations of sites in the United States for which observers have reported data via Nature's Notebook. Sites range from individual plants to areas encompassing many plants and animals and may have been visited once or for many successive years. These data enable phenological research on a scale that would otherwise be impossible. 


\section{Nature's Notebook by the Numbers,} as of January 2020

20 million phenology records

17,000 total observers

500 Local Phenology Programs (LPPs)

13,000 observation sites

67,000 observed organisms

82 publications using Nature's Notebook data

\section{Collecting and Maintaining High-Quality Data}

Phenology data are most valuable when collected regularly, at the same locations over many years, and when the collection is guided by robust monitoring methods to ensure data quality. The USA-NPN offers a suite of training resources to support the Nature's Notebook program, including online learning modules, web pages, handbooks, and more. Participants are instructed to track individual plants through time to capture their unique responses to environmental conditions from year to year. Observers are provided with relevant resources, reminders to observe, tips on how to identify species and how to observe, and summarized results of their data collection efforts. Learn more at https://usanpn.org/data/quality.

\section{"The USA-NPN data represent the gold} standard for monitoring."

\section{-Susan Mazer, Professor}

University of California, Santa Barbara

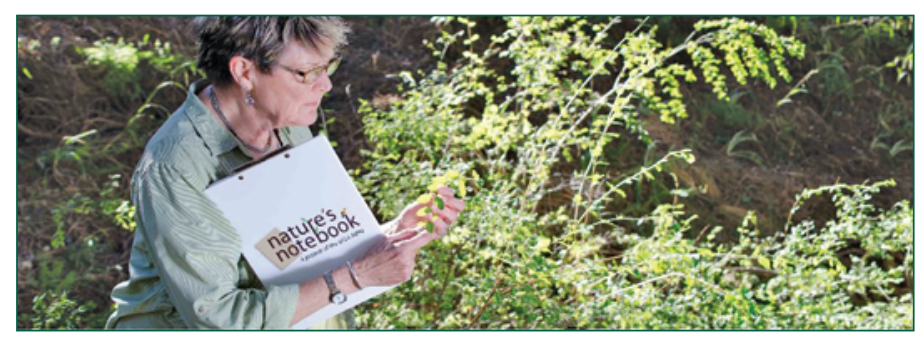

A Nature's Notebook observer inspects a leaf to determine the phenological stage.

\section{Local Phenology Programs: Collaborative Community Science}

The most valuable phenology data are collected through collaborative community science. Local training, support, and the shared responsibility of group monitoring ensure that phenology data are collected regularly and at the same locations over many years. LPPs are community or regional groups that engage members in phenology monitoring. Programs range from discrete, local-scale efforts to regional networks made up of multiple organizations working toward a common goal. The USA-NPN encourages LPPs to identify a locally significant research or management question to answer with phenology data or an outreach or educational outcome to achieve. LPP members are guided by one or more Local Phenology Leaders (LPLs) who assist with training, scheduling, and management.

The USA-NPN supports LPPs by providing:

-A 10-week online LPL certification program

- LPP planning guides

- A customizable dashboard that tracks details about participation and site-based data

- Training slides, handouts, and other resources for workshops and outreach events

- A Community of Practice that brings together USA-NPN staff and LPLs to share resources and lessons learned

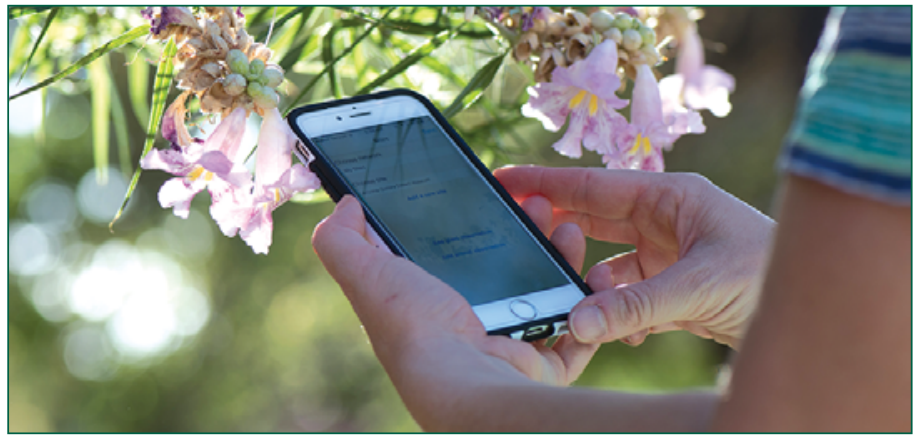

An observer submitting data in the field using the Nature's Notebook mobile application.
Eastern cottonwood/Flowers or flower buds (2019)

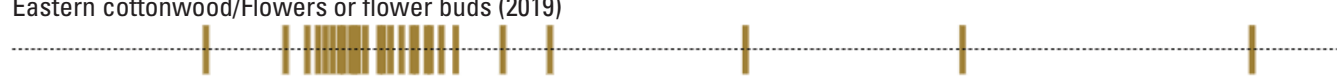

Eastern cottonwood/Fruits (2019)

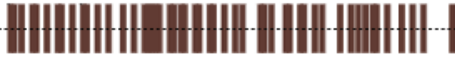

Eastern cottonwood/Breaking leaf buds (2019)

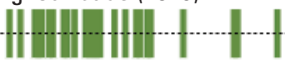

Eastern cottonwood/Leaves (2019)

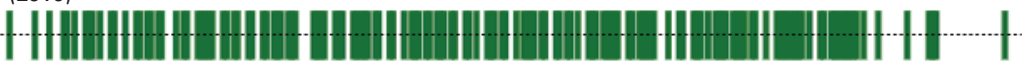

Eastern cottonwood/Colored leaves (2019)

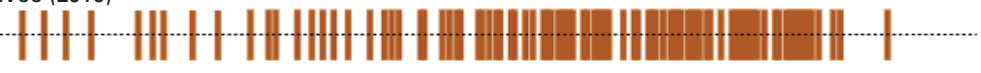

Figure 2. Visualization of the timing of five different phenological stages for eastern cottonwoods (Populus deltoides) from the Albuquerque, New Mexico, area in 2019. Colored lines indicate dates when an observer reported "yes" for that life cycle stage. Observational data were provided by volunteer scientists through Nature's Notebook and contribute to our understanding of phenological events for this species.

Jan. Feb. Mar. Apr. May June July Aúg. Sept. O'́l. Nov. Dec.

USA National Phenology Network, www.usanpn.org 


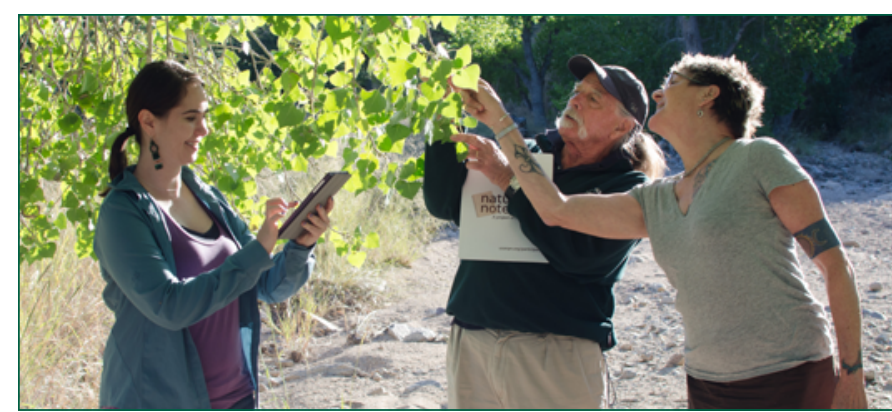

Volunteer scientists collect phenology data on a Fremont cottonwood tree near Tucson, Arizona.

\section{Combining Forces With Partners To Advance the Field of Phenology}

Nature's Notebook is used by hundreds of organizations across the country to meet organizational goals. Groups such as National Wildlife Refuges, National Parks, botanical gardens and arboreta, universities, and community nature centers collaborate with the USA-NPN to meet their scientific, educational, and outreach objectives. The USA-NPN is keen to partner with organizations that want to collect or use phenology data and information. Our staff will work closely with you to identify the best ways to leverage USA-NPN resources to accomplish your organization's goals.

Some uses of data from Nature's Notebook include establishing baseline species information, detecting changes in the timing of plant and animal activity, identifying species that may be falling out of synchrony with one another, and engaging students and the public in answering local questions. Three case studies are described below.

\section{A Customizable Monitoring Platform To Support Natural Resource Management Goals}

Located on a former farm south of Albuquerque, New Mexico, the Valle de Oro National Wildlife Refuge is transitioning into an urban oasis for wildlife and people. Data collected by volunteer scientists and submitted to Nature's Notebook are used by refuge staff to decide when to time restoration activities to avoid disrupting the breeding activity of birds and to promote the growth of keystone species like the eastern cottonwood (fig. 2).

The USA-NPN provides to Federal partners - such as the U.S. Fish and Wildlife Service (USFWS) - the standardized data collection protocols, data infrastructure, and management tools to meet management and outreach objectives. Refuges create phenology monitoring programs that enable management to make science-based decisions while contributing to a national picture of environmental change.

\author{
"Refuge biologists are seeing a lot of \\ changes. Through our partnership with \\ USA-NPN, we're able to formally document \\ the changes that we're seeing."

$$
\text { -Sue Wilder, USFWS Ecologist }
$$

\section{Crowdsourcing Science To Study Invasive Species}

Do invasive shrubs have a competitive edge over native shrubs because they have a longer leafing period each year? Do these early-leafing invaders block sunlight and hinder the growth of native species? Hoping to answer these questions, researchers at Penn State University, Pennsylvania, partnered with Nature's Notebook to create the Shady Invaders campaign. Volunteer scientists collected the relevant data - primarily in the eastern United States - from 2016 until the campaign ended in 2018. These data were gathered on a scale and with a frequency that would not otherwise have been feasible by conventional research methods. Through collaborations like these, the USANPN helps researchers across the country get the data that they need to advance the field of phenology.

\section{"The data collected by Shady Invaders}

volunteers revealed regional patterns in the differences between native and invasive shrubs. I never would have been able to collect these highquality data across this large region on my own." -Erynn Maynard-Bean, Postdoctoral Researcher Penn State University

\section{Inspiring Students To Collect Data That Scientists and Resource Managers Can Use}

Radford University faculty and students are monitoring seasonal changes in plant and animal communities in Virginia's Appalachian Mountains. Students are involved in each part of the scientific process to investigate the impacts of invasive shrubs on the phenology of native shrubs and wildflowers and to document the activity periods of wildlife by using motionsensitive wildlife cameras.

Nature's Notebook is a comprehensive tool for teaching students about ecosystems and how species respond to change. Student-collected observations become part of a data resource that will be used by scientists and decision makers for many decades to come.

\section{'Nature's Notebook provides my undergraduate} biology majors with an opportunity to develop original research questions of scientific or conservation value, learn how to accurately collect phenology data to address their questions, analyze and interpret their results to address broad issues, and communicate results to professional and public audiences."

-Christine Small, Professor, Radford University, Virginia 


\section{How the Data Are Being Used}

Phenology data may help to predict threats to people and the environment, such as wildfires, droughts, and floods. These data can also help to decide when to time certain events, such as when to harvest crops, irrigate land, conduct controlled burns in forests, or even when to plan nature-based recreational activities such as wildflower festivals.

Nature's Notebook data have supported a wide range of scientific discoveries, some of which have informed natural resource management and human health decisions. Sources have been given for each example below:

- Spring is occurring earlier in 76 percent of the U.S. National Parks and National Wildlife Refuges that were studied; about 50 percent of parks and refuges are experiencing extremely early onsets of spring (Monahan and others, 2016; Waller and others, 2018)

- Invasive buffelgrass (Pennisetum ciliare) begins growing quickly after a rainfall, giving managers an optimal window for herbicide treatment (Wallace and others, 2016)

- Allergenic ragweed (Ambrosia artemisiifolia), which is limited to areas where its seeds can mature before winter frost, is predicted to expand its range under climatic warming (Chapman and others, 2013)

- The timing of flowering is best predicted by maximum temperature, number of frost-free days, and quantity of precipitation as snow (Park and Mazer, 2018)

- Leaf out and flowering in oaks in water-limited systems occur earlier and more intermittently than in oaks in the central and eastern United States (Gerst and others, 2017)

- Over the past 30 years, the growing season has lengthened by approximately 1 week in the eastern United States and upper Rocky Mountains (Yue and others, 2015)

- By the end of this century, spring may arrive 3 weeks earlier across the United States (Allstadt and others, 2015)

- Daytime temperatures, rather than nighttime temperatures, trigger leafing in temperate plants (Piao and others, 2015)

- By the end of this century, fall color changes may occur later than they did in 2006-2010 in regions such as the northeastern United States (Jeong and Medvigy, 2014)

Acknowledgments.-The USGS and the University of Arizona provide major support to the USA-NPN. The USA-NPN collaborates with the U.S. Fish and Wildlife Service, National Park Service, National Aeronautics and Space Administration, National Science Foundation, National Oceanic and Atmospheric Administration, and U.S. Forest Service, as well as hundreds of other management agencies, universities, botanical gardens, nature centers, and other organizations. All photographs by Brian F. Powell, used with permission.

\section{References Cited}

Allstadt, A.J., Vavrus, S.J., Heglund, P.J., Pidgeon, A.M., Thogmartin, W.E., and Radeloff, V.C., 2015, Spring plant phenology and false springs in the conterminous US during the 21st century: Environmental Research Letters, v. 10, no. 10, 24 p., accessed January 21, 2020, at https://doi.org/10.1088/1748-9326/10/10/104008.

Chapman, D.S., Haynes, T., Beal, S., Essl, F., and Bullock, J.M., 2013, Phenology predicts the native and invasive range limits of common ragweed: Global Change Biology, v. 20, no. 1, p. 192-202, accessed January 21, 2020, at https://doi.org/10.1111/gcb.12380.

Gerst, K.L., Rossington, N.L., and Mazer, S.J., 2017, Phenological responsiveness to climate differs among four species of Quercus in North America: Journal of Ecology, v. 105, no. 6, p. 1610-1622, accessed January 21, 2020, at https://doi.org/10.1111/1365-2745.12774.

Jeong, S.J., and Medvigy, D., 2014, Macroscale prediction of autumn leaf coloration throughout the continental United States: Global Ecology and Biogeography, v. 23, no. 11, p. 1245-1254, accessed January 21, 2020, at https://doi.org/10.1111/geb.12206.

Monahan, W.B., Rosemartin, A.H., Gerst, K.L., Fisichelli, N.A., Ault, T., Schwartz, M.D., Gross, J.E., and Weltzin, J.F., 2016, Climate change is advancing spring onset across the U.S. national park system: EcoSphere, v. 7, no. 10, 17 p., accessed January 21, 2020, at https://doi.org/10.1002/ecs2.1465.

Park, I.W., and Mazer, S.J., 2018, Overlooked climate parameters best predict flowering onset-Assessing phenological models using the elastic net: Global Change Biology, v. 24, no. 12, p. 5972-5984, accessed Janaury 21, 2020, at https://doi.org/10.1111/gcb.14447.

Piao, S., Tan, J., Chen, A., Fu, Y.H., Ciais, P., Liu, Q., Janssens, I.A., Vicca, S., Zeng, Z., Jeong, S.J., Li, Y., Myneni, R.B., Peng, S., Shen, M., and Peñuelas, J., 2015, Leaf onset in the Northern Hemisphere triggered by daytime temperature: Nature Communications, v. 6, article 6911, 8 p., accessed January 21, 2020, at https://doi.org/10.1038/ncomms 7911.

Wallace, C.S.A., Walker, J.J., Skirvin, S.M., Patrick-Birdwell, C., Weltzin, J.F., and Raichle, H., 2016, Mapping presence and predicting phenological status of invasive buffelgrass in southern Arizona using MODIS, climate and citizen science observation data: Remote Sensing, v. 8, no. 7, article 524, 24 p., accessed January 21, 2020, at https://doi.org/10.3390/rs8070524.

Waller, E.K., Crimmins, T.M., Walker, J.J., Posthumus, E.E., and Weltzin, J.F., 2018, Differential changes in the onset of spring across US National Wildlife Refuges and North American migratory bird flyways: PLOS One, v. 13, no. 9, article e0202495, 24 p., accessed January 21, 2020, at https://doi.org/10.1371/journal.pone.0202495.

Yue, X., Unger, N., Keenan, T.F., Zhang, X., and Vogel, C.S., 2015, Probing the past 30-year phenology trend of US deciduous forests: Biogeosciences, v. 12, no. 15, p. 4693-4709, accessed January 21, 2020, at https://doi.org/10.5194/bg-12-4693-2015.

—By Erin E. Posthumus, ${ }^{1}$ Mark P. Miller, ${ }^{2}$ and Theresa Crimmins ${ }^{1}$ ${ }^{1}$ USA National Phenology Network. ${ }^{2}$ U.S. Geological Survey.
For more information:

Office of the Associate Director, Ecosystems Mission Area

U.S Geological Survey, Mail Stop 300, 12201 Sunrise Valley Drive

Reston, VA 20192

E-mail: partners@usanpn.org
The USA-NPN tools and data products are compliant with Federal information policy, ensuring data quality, discovery, accessibility, reuse, and long-term curation in a National Phenology Database. Standardized observation protocols are peer reviewed and published. Data are freely available for download and can be explored via the Visualization Tool. USA-NPN infrastructure is in compliance with the Privacy Act and the Paperwork Reduction Act (OMB Control: 1028-0103). 